\title{
Ethical Judgement in UK Business Students: Relationship with Motivation, Self-Compassion and Mental Health
}

\author{
Yasuhiro Kotera $^{1}$ (D) Elaine Conway ${ }^{2} \cdot$ William Van Gordon ${ }^{1}$
}

Published online: 30 November 2018

(C) The Author(s) 2018

\begin{abstract}
Business ethics have come under increasing scrutiny recently due to various corporate scandals. This has prompted a need for research into the characteristics of people drawn to the business world and the education they receive. This study (i) evaluates the levels of ethical judgement, mental health, motivation, and self-compassion in $144 \mathrm{UK}$ business students and (ii) assesses the relationships between these variables. A high proportion of respondents (i) believed that other students would behave unethically, whilst they themselves would not, and (ii) had a high level of anxiety, extrinsic motivation and self-compassion. Extrinsic motivation was associated with participants' belief that others would behave unethically, whilst intrinsic motivation was associated with strict ethical judgement and self-compassion. Extrinsic motivation and self-compassion were significant explanatory variables for students' ethical judgement, and self-compassion was a significant explanatory variable for mental health symptoms. This study is unique in examining the facets of ethics, mental health, self-compassion and motivation in business students. Findings have implications for both educators and practitioners since improving ethical behaviour in the future workforce may be achieved by augmenting future employees' levels of self-compassion and intrinsic motivation, rather than solely administering "ethics training" that has been found to be of limited value. Findings also indicate that such an approach may have utility for improving business students' mental health.
\end{abstract}

Keywords Ethical judgement · Business students · Mental health · Self-compassion

There have been an increasing number of corporate scandals in recent years (van Luttervelt 2006). For example, Volkswagen allegedly installed software into their cars that provided false environmental emissions measurements (Matthews and Gandel 2015), and Wells Fargo

Yasuhiro Kotera

Y.Kotera@derby.ac.uk

1 Centre for Psychological Research, University of Derby, Kedleston Road, Derby, Derbyshire DE22 $1 \mathrm{~GB}, \mathrm{UK}$

2 Derby Business School, University of Derby, Kedleston Road, Derby, Derbyshire DE22 1GB, UK 
allegedly created fake accounts with real customers' names in order to increase the number of credit cards issued (Matthews and Heimer 2016). Arthur Anderson, one of the largest accounting firms in the world, was adversely affected in the wake of the Enron scandal in 2001, after being judged to have been complicit and negligent with regard to Enron's management activities (Odonkor 2017). In the long term, organisations utilising unethical practices usually suffer in a variety of ways including (for example) (i) reduction in stock price (Long and Rao 1995; Lund Dean et al. 2010), (ii) damaged brand image (Cialdini et al. 2004), (iii) lower worker productivity resulting from a reduction in organisational morale (Webley and More 2003; Varca and James-Valutis 1993) and (iv) poorer employee retention and recruitment (Ethics Resource Center 2014).

Unsurprisingly, awareness of ethical practices in business has been steadily increasing amongst workers, academics and government administrations (Ahmed et al. 2003). Indeed, good ethical practice is now much more highly regarded as fundamental to acceptable business behaviour. In line with this increased awareness of the importance of business ethics, some researchers have asserted that one key determinant of unethical business conduct may be inadequate training as part of business education programmes (Ghoshal 2005). This assertion is supported by the fact that business students appear to be more tolerant of unethical behaviour than other student groups (Cole and Smith 1996). For example, a study $(n \approx 5000)$ comparing business and non-business students from 32 graduate schools in North America reported that business students cheat more than nonbusiness peers (56\% vs. 47\%; Mccabe et al. 2006). The same study also reported that business students' cheating is correlated with (i) perceived peer behaviour, (ii) perceived certainty of being reported and (iii) the understanding and acceptance of academic integrity policies.

In order to counter this problem, more and more business schools have started to incorporate ethics education into their curriculum, with the result that approximately $70 \%$ of the world's top business schools now teach ethics on their courses (Litzky and MacLean 2011). In line with these developments, one study of contemporary business students $(n \approx 1700)$ reported that $75 \%$ of business students believe that companies should have a social responsibility beyond making profit (Haski-Leventhal and Concato 2016). Similarly, it should be noted that many students (including business students) are motivated by factors that are more ethically orientated such as finding meaning in what they do vs. earning a high salary per se (e.g. FTI Consulting 2015; Hurst et al. 2016).

However, notwithstanding the integration of ethics training into business education curriculum, the effectiveness of such training has been questioned. For example, a study found that attending a business ethics course did not have any significant effect on students' ethical judgement (Jewe 2008). Another study reported that business students still had the highest rate of cheating amongst university students after completion of ethical training (Lampe and Engleman-Lampe 2012). Furthermore, a meta-analysis found that business ethics education only had a slight impact on students' ethical judgement (Waples et al. 2009). Such findings have led to investigations into the psychological uniqueness of business students compared to non-business students, with findings indicating that (i) business students can be more narcissistic and less empathetic than non-business peers (Sautter et al. 2008) and (ii) business students' narcissism is positively associated with unethical judgements (Brown et al. 2010).

A further risk factor for impaired ethical judgement is mental health issues (Hindmarch et al. 2013). This is particularly relevant for business students because in addition to constituting the largest student group in UK universities (Higher Education Statistics Agency 
[HESA] 2018), the number of business students with mental health problems reached 35,500 in 2015, which was almost triple the number of business students identified as having mental health problems in 2010 (HESA 2018). Furthermore, in addition to the high prevalence, studies have noted that the severity of business students' mental health problems can be relatively high (Kotera et al. 2018a). More specifically, business students have been shown to have higher levels of stress, burnout, alcohol use and depression than other student groups (Dahlin et al. 2011). This observation may be related to the culture of business programmes in which business students (i) tend to study individually rather than as a group, causing a lack of social support, and (ii) are often engaged with business sectors from the beginning of the programme which tends to increase sociable alcohol consumption (Dahlin et al. 2011).

Whilst business educators are generally aware of the aforementioned mental health issues amongst their students, only a minority teach stress management as part the syllabus (Matthews 2017). According to Kotera et al. (2018a), "the gap between awareness of the need for stress management skills and provision of such training in MBA programmes suggests that whilst some business educators are aware of mental health problems among their students, they may not have the knowledge or resources to address the problem" (p. 1). A better scientific understanding of the relationship between ethics and mental health in business students could help to inform the design and provision of both ethics and mental health training by business education providers.

In terms of understanding how business students formulate and apply ethical judgements, recent research findings indicate that other factors likely to play an important role are motivation and self-compassion. More intrinsic forms of motivation (e.g. finding meaning in one's studies) are typically associated with better mental health outcomes and ethically appropriate behaviour vs. more extrinsic forms of motivation (e.g. working for financial reward or the promise of promotion; Kasser and Ryan 2001; Kotera et al. 2018b; Sheldon and Kasser 1995, 1998; Williams et al. 2000). Similarly, self-compassion appears to serve as a protective factor for maladaptive psychosocial functioning in university student groups (Kotera et al. 2018a). Self-compassion is a healthy form of self-acceptance that involves treating oneself kindly when facing inadequacy (Neff 2003a, b), and accessing one's wisdom and awareness inwardly (Brown and Ryan 2003; Langer 1989, 2005; Wallace and Shapiro 2006). Self-compassion is positively associated with mental well-being in various student samples (Kotera et al. 2018a; Neely et al. 2009; Ying 2009). For example, (i) self-compassion was found to be significantly related to students' mental health in American undergraduate students (Neely et al. 2009) and (ii) the positive subscales for self-compassion (i.e. mindfulness, common humanity, self-kindness) were negatively associated with depression in postgraduate social work students in America (Ying 2009).

A compassionate outlook (whether towards oneself or others) relates to ethical judgement because it is associated with less egoistic bias, leading to reduced acceptance of an individual's own unethical conduct (Breines and Chen 2012; Shonin et al. 2017; Van Gordon et al. 2014, 2016). Indeed, in a cross-cultural sample, students with higher levels of self-compassion were found to be less accepting of their own unethical behaviours (Wang et al. 2017). Selfcompassion has also been shown to reduce the likelihood of an individual perceiving neutral feedback as negative, thus contributing to more realistic self-evaluation (Leary et al. 2007) and more stable self-worth (Neff and Vonk 2009). When an individual's self-worth is threatened, it is generally understood that this increases the risk of them lowering their ethical standards (Jordan and Monin 2008). 
Given the likely_-but as yet unexplored - interplay between ethical judgement, mental health symptoms, motivation and self-compassion in business students, the aims of this study are to (i) evaluate the levels of these four variables in a sample of UK university business students, (ii) explore the relationships between the variables and (iii) identify significant explanatory variables for ethical judgement and mental health in UK business students.

\section{Methods}

\section{Sample Selection}

All participants were aged 18 years or older and were undergraduate male and female business students studying at a UK university in the East Midlands. Students who were on a study break at the time of the study were excluded from the study. Participants were recruited using opportunity sampling via study flyers and announcements distributed by programme tutors (no course credits or other forms of compensation were awarded for participation).

Out of 150 full-time undergraduate students who expressed an interest in participating in the study, 144 (69 male, 69 female, 6 gender not declared) completed self-reported measures assessing ethical values, academic motivation, self-compassion and mental health. Participants' age range was $18-57$ years old $\left(M_{\mathrm{age}}=21.11, \mathrm{SD}_{\mathrm{age}}=5.64\right)$. One-hundred-and-two students were British, and 41 were international students (22 other Europeans, 9 Asians, 7 Africans, 1 North American, 1 South American and 1 Oceanian). One student did not report their nationality.

This was a separate parallel study in which the same group of students also attended assessments relating to shame and its interaction with other variables. The results from the parallel study are reported elsewhere (Kotera et al. 2018a). Ethical approval was granted by the university's research ethics committee, and students were made aware of mental health support services inside and outside the university in the event they wished to seek professional help for any mental health issues. Informed consent was obtained from all participants included in the study.

\section{Instruments}

The Multidimensional Ethics Scale (MES) provides 12 vignettes which participants assess from an ethical standpoint. Responses are scored on a seven-point Likert scale (1 being least ethical to 7 being most ethical; Reidenbach and Robin 1990). The MES is a well-established scale, with high internal consistency (Cronbach's alphas are 0.71-0.92 [Agle et al. 2014]). An example of one of the vignettes is: "A senior director who earns $£ 100,000$ per year claimed $£ 3,000$ in expenses to which he was not entitled. The company he works for makes several million pounds in profit each year". The following five dimensions of the MES were selected for the purposes of this study: (i) acceptable/unacceptable, (ii) ethical/unethical, (iii) culturally acceptable/unacceptable, (iv) self (i.e. I would do it) and (v) other (i.e. other people my age would do it). These five dimensions were selected because they are the components that most directly related to ethical judgement (Comegys et al. 2013; Shields et al. 2013). In the current sample, the Cronbach's alpha for the five MES dimensions was $0.72-0.82$, demonstrating a high level of internal consistency.

The Depression Anxiety and Stress Scale (DASS-21) is a short form of the DASS-42 (Lovibond and Lovibond 1995). It comprises 21 items scored on a four-point Likert scale. The items are categorised into three seven-item subscales; depression (e.g. "I felt that I had nothing 
to look forward to"), anxiety (e.g. "I felt I was close to panic") and stress (e.g. "I found it difficult to relax"). In the current sample, the Cronbach's alpha for DASS was 0.76-0.89, demonstrating a high level of internal consistency.

The Academic Motivation Scale (AMS) is a 28-item self-report measure that evaluates the levels of seven different types of motivation: amotivation, three types of extrinsic motivation (external, introjected and identified regulation) and three types of intrinsic motivation (to know, to accomplish and to experience stimulation). In the current study, the three subscales for intrinsic motivation and the three subscales for extrinsic motivation were combined as "intrinsic motivation (IM)" and "extrinsic motivation (EM)", respectively. Each type of motivation is assessed using four items on a seven-point Likert scale (from $1=$ "Does not correspond at all" to $7=$ "Corresponds exactly"). In the current sample, the Cronbach's alpha for AMS was 0.73-0.84, demonstrating a high level of internal consistency.

The Self-Compassion Scale-Short Form (SCS-SF) is a shortened version of the SelfCompassion Scale, comprising 12 five-point Likert items (Neff 2003b) including "When I fail at something important to me I become consumed by feelings of inadequacy". The fivepoint responses range from 1 (almost never) to 5 (almost always). In the current sample, the Cronbach's alpha for SCS was 0.75 .

\section{Analytical Procedure}

All data collected was initially screened for outliers and the rates of scores over the midpoint within the score range were calculated (e.g. 4 in the range of 1-7). After screening the data for the assumptions of various parametric tests, correlations between ethics, mental health symptoms, motivation and self-compassion were explored. Finally, multiple regression analyses were conducted to examine the best explanatory variables of student's ethical judgement and mental health symptoms.

\section{Results}

Analyses were conducted using IBM SPSS version 24.0. One score in EMID and the DASS21 stress subscale, two scores in EMRE and five scores in AM were identified as outliers using the outlier labelling rule (Hoaglin and Iglewicz 1987). The outliers were winsorised in line with recommendations by Tukey (1962). Skewness values ranged from -0.83 to 1.47 , and kurtosis values from -0.52 to 1.11 (Table 1 ).

Amongst the MES subscales, a high proportion of business students reported that other students would act unethically based on the behaviours described in the vignettes ("Other" subscale), whilst a low proportion reported that the described behaviours were acceptable ("Accept"), ethical ("Ethical"), culturally acceptable ("Culture") and that they would do it themselves ("Self"). There were significant differences between the Other score and the rest of the four subscale scores $(p>0.01)$. A high proportion of business students scored over the mid-point for self-compassion.

\section{Correlations}

Out of a total of 12 subscales (i.e. across all psychometric tests), data in seven subscales were square-root-transformed to satisfy the assumption of normality: culture, self, depression, 
Table 1 Descriptive statistics of ethics, mental health, motivation and self-compassion of business students, and comparison with caring profession students in mental health and motivation

\begin{tabular}{|c|c|c|c|c|c|c|c|}
\hline \multirow[b]{2}{*}{ Subscales (range) } & \multicolumn{4}{|c|}{ Business students } & \multicolumn{3}{|c|}{ Caring profession students } \\
\hline & $M$ & $\mathrm{SD}$ & $N$ & Percent over midpoint & $M$ & SD & $N$ \\
\hline Accept $(1-7)$ & $2.91 \mathrm{a}$ & 0.79 & 144 & 11.11 & & & \\
\hline Ethical (1-7) & $2.59 \mathrm{~b}$ & 0.78 & 144 & 4.17 & & & \\
\hline Culture (1-7) & $3.12 \mathrm{c}$ & 0.91 & 144 & 16.67 & & & \\
\hline Self (1-7) & $2.75 \mathrm{~d}$ & 0.99 & 144 & 13.89 & & & \\
\hline Other (1-7) & $4.00 \mathrm{abcd}$ & 0.98 & 144 & 52.08 & & & \\
\hline Dprn $(0-42)$ & 10.56 & 9.75 & 144 & 15.97 & 10.33 & 7.14 & 116 \\
\hline Anx $(0-42)$ & $12.75 \mathrm{~g}$ & 9.60 & 144 & 18.75 & $10.41 \mathrm{~g}$ & 7.80 & 116 \\
\hline Strs $(0-42)$ & 14.65 & 10.72 & 144 & 26.39 & 15.71 & 8.53 & 116 \\
\hline IMK (4-28) & 20.29 & 4.91 & 144 & 83.33 & 20.54 & 5.27 & 116 \\
\hline IMA (4-28) & 17.30 & 5.72 & 144 & 64.58 & 18.31 & 5.53 & 116 \\
\hline IMES (4-28) & 14.69 & 5.32 & 144 & 43.75 & 15.11 & 5.55 & 116 \\
\hline EMID (4-28) & $22.88 \mathrm{e}$ & 4.16 & 144 & 93.75 & $21.84 \mathrm{e}$ & 4.02 & 116 \\
\hline EMIT (4-28) & 20.42 & 4.96 & 144 & 85.42 & 20.15 & 5.65 & 116 \\
\hline EMRE (4-28) & $21.44 \mathrm{f}$ & 4.66 & 144 & 88.89 & $19.84 \mathrm{f}$ & 5.56 & 116 \\
\hline AM (4-28) & 7.05 & 4.04 & 144 & 9.03 & 7.05 & 3.96 & 116 \\
\hline $\mathrm{SC}(12-60)$ & 36.80 & 7.58 & 144 & 61.11 & & & \\
\hline
\end{tabular}

Dpn depression, Anx anxiety, Strs stress, IMK intrinsic motivation to know, IMA intrinsic motivation towards accomplishment, IMS intrinsic motivation to experience stimulation, EMID extrinsic motivation identified, EMIJ extrinsic motivation introjected, EMER extrinsic motivation external regulation, AM amotivation, SC selfcompassion

Small letters indicate that there was significant difference between the two groups

anxiety, stress, EM and AM. Pearson's correlations were used to examine relationships between ethics, mental health symptoms, motivation and self-compassion Table 2.

Intrinsic motivation was negatively related to ethical acceptability, and extrinsic motivation was positively related to others' ethical behaviours. Intrinsic motivation was positively related to age. Gender was positively related to ethical acceptability, ethical judgement, cultural acceptability and self-judgement, whilst age was negatively related to each of four aforementioned subscales (i.e. ethical acceptability, ethical judgement, cultural acceptability and selfjudgement). Mental health symptoms were positively related to amotivation, and negatively related to self-compassion. Self-compassion was related to intrinsic motivation and age. There was no significant correlation between ethics and mental health, nor between ethics and selfcompassion.

\section{Regression}

Finally, multiple regression analyses were conducted to explore the relative contribution of (i) motivation, mental health symptoms and self-compassion towards ethics (Table 3) and (ii) ethics, motivation and self-compassion towards mental health symptoms (Table 4). At step 1, gender and age were entered to adjust for their effects, and at step 2, all of the related scores were entered. Because of the many predictor variables, adjusted coefficient of determination (Adj. $R^{2}$ ) are reported. Multicollinearity was not a concern as the tolerance values were 0.28 or higher.

Extrinsic motivation was a significant explanatory variable for others' ethical behaviours. Self-compassion was a significant explanatory variable for ethical judgement and cultural acceptability. Age and gender were significant explanatory variables for the 


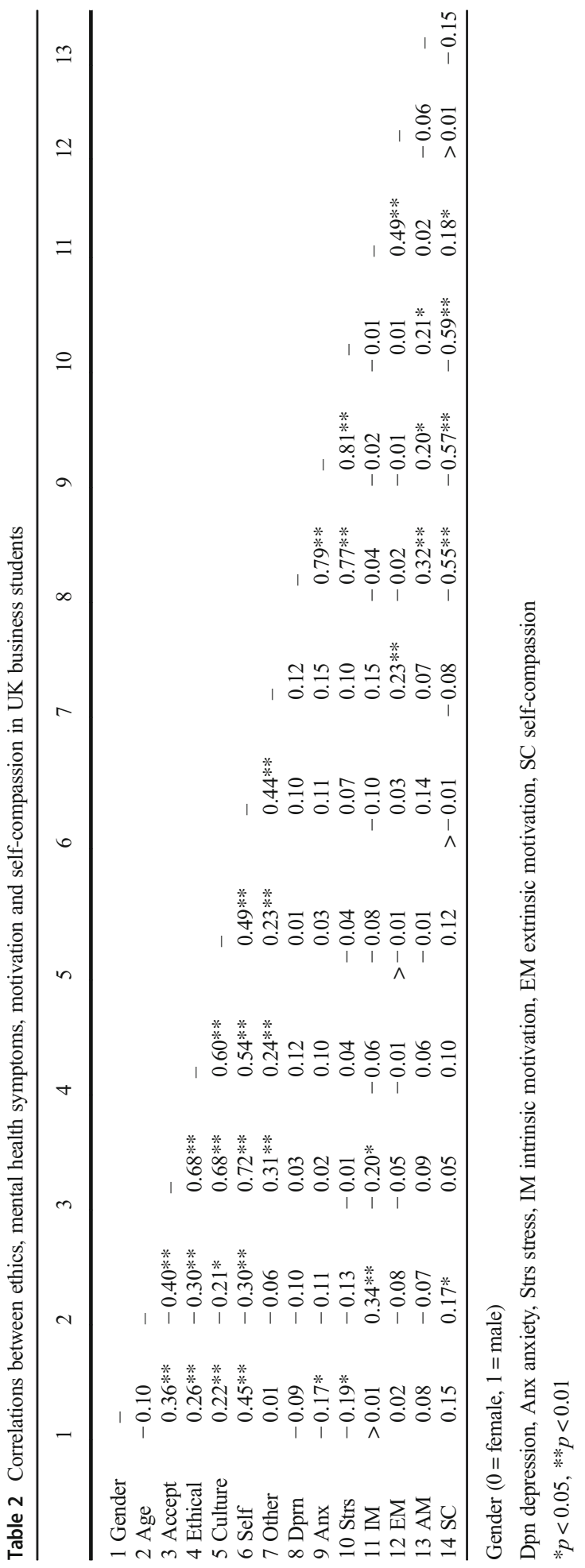




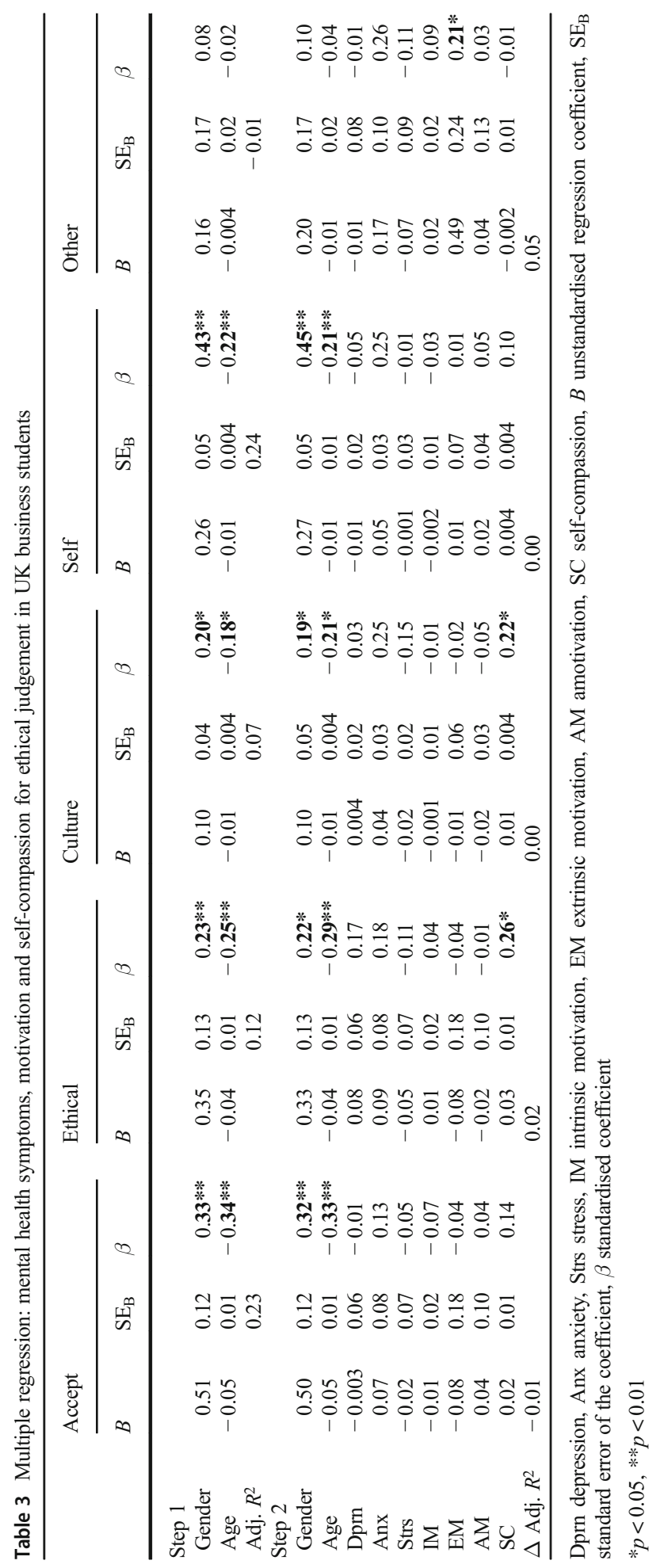


Table 4 Multiple regression: ethical judgement, motivation and self-compassion for mental health symptoms in UK business students

\begin{tabular}{|c|c|c|c|c|c|c|c|c|c|}
\hline & \multicolumn{3}{|c|}{ Depression } & \multicolumn{3}{|c|}{ Anxiety } & \multicolumn{3}{|l|}{ Stress } \\
\hline & $B$ & $\mathrm{SE}_{\mathrm{B}}$ & $\beta$ & $B$ & $\mathrm{SE}_{\mathrm{B}}$ & $\beta$ & $B$ & $\mathrm{SE}_{\mathrm{B}}$ & $\beta$ \\
\hline \multicolumn{10}{|l|}{ Step 1} \\
\hline Gender & -0.33 & 0.31 & -0.09 & -0.54 & 0.26 & $-0.18 *$ & -0.63 & 0.28 & $-0.19 *$ \\
\hline Age & -0.02 & 0.03 & -0.06 & -0.02 & 0.02 & -0.06 & -0.03 & 0.03 & -0.08 \\
\hline Adj. $R^{2}$ & & $<0.01$ & & & 0.02 & & & 0.03 & \\
\hline \multicolumn{10}{|l|}{ Step 2} \\
\hline Gender & -0.23 & 0.28 & -0.06 & -0.50 & 0.24 & $-0.17 *$ & -0.53 & 0.26 & $-0.16^{*}$ \\
\hline Age & 0.01 & 0.03 & 0.03 & 0.01 & 0.02 & 0.02 & -0.01 & 0.03 & -0.03 \\
\hline Accept & -0.39 & 0.23 & -0.17 & -0.40 & 0.25 & -0.21 & -0.25 & 0.27 & -0.12 \\
\hline Ethical & 0.49 & 0.23 & $0.22 *$ & 0.30 & 0.19 & 0.15 & 0.23 & 0.21 & 0.11 \\
\hline Culture & 0.15 & 0.68 & 0.02 & 0.47 & 0.58 & 0.08 & -0.07 & 0.63 & -0.01 \\
\hline Self & 0.48 & 0.66 & 0.08 & 0.90 & 0.56 & 0.18 & 0.80 & 0.60 & 0.15 \\
\hline Other & 0.06 & 0.15 & 0.03 & 0.10 & 0.13 & 0.06 & $>-0.01$ & 0.14 & $>-0.01$ \\
\hline IM & 0.02 & 0.04 & 0.06 & 0.04 & 0.03 & 0.11 & 0.06 & 0.03 & 0.16 \\
\hline EM & -0.26 & 0.37 & -0.06 & -0.42 & 0.31 & -0.12 & -0.38 & 0.34 & -0.10 \\
\hline $\mathrm{AM}$ & 0.68 & 0.19 & $0.26 * *$ & 0.28 & 0.16 & 0.13 & 0.34 & 0.17 & 0.14 \\
\hline $\mathrm{SC}$ & -0.12 & 0.02 & $-0.51 * *$ & -0.11 & 0.02 & $-0.53 * *$ & -0.12 & 0.02 & $-0.55 * *$ \\
\hline$\Delta$ Adj. $R^{2}$ & 0.35 & & & & 0.32 & & & 0.31 & \\
\hline
\end{tabular}

IM intrinsic motivation, EM extrinsic motivation, AM amotivation, SC self-compassion, $B$ unstandardised regression coefficient, $\mathrm{SE}_{\mathrm{B}}$ standard error of the coefficient, $\beta$ standardised coefficient

$* p<0.05, * * p<0.01$

ethical acceptability, ethical judgement, cultural acceptability and ethical behaviours relating to the self (Table 3 ). The ethics, motivation and self-compassion measures accounted for $31-35 \%$ of the variance in the mental health symptoms, after adjusting for demographic information. Self-compassion was a significant explanatory variable for all the mental health symptoms. Gender was a significant explanatory variable for anxiety and stress. Ethical judgement and amotivation were significant explanatory variables for depression (Table 4).

\section{Discussion}

A high proportion of business students scored over the midpoint in respect of self-compassion (61.11\% scored over 36 from a range of 12-60) and believing others' unethical behaviours (52.08\% scored over 4 from a range of 1-7). Business students' intrinsic motivation was negatively related to their ethical acceptability, whilst extrinsic motivation was positively associated with others' ethical behaviours. All of the mental health symptoms were negatively related to self-compassion. Finally, multiple regression analyses demonstrated that extrinsic motivation was a significant explanatory variable for others' ethical behaviours. Selfcompassion was a significant explanatory variable for ethical judgement, cultural acceptability and all of the mental health symptoms.

The business students demonstrated a high level of anxiety that may offer insight into the nature of mental health problems experienced by this population group. Indeed, limited previous research has focussed on the general mental health of business students, and the specifics of their mental health problems thus remain unclear. Although anxiety and stress are 
similar constructs, anxiety is one of the adverse effects of stress and can make individuals apprehensive of what awaits them in the future (Groberman 2017). Therefore, business students' high levels of anxiety could be explained by the fact that for many business students, the path to a final career is often unstructured and uncertain (Kotera et al. 2018a). Indeed, research shows that individuals who have made and declared their intent to enter a specific career are less likely to suffer from "career choice anxiety" (Brown and Strange 1981; Germeijs et al. 2006; Kimes and Troth 1974).

The positive correlation observed in the current study between anxiety and other mental health symptoms has implications for how business education providers approach the challenge of building resilience to mental health issues as well as how to structure career planning and support. More specifically, targeting reductions in anxiety by helping business students develop clearer career pathways could be an efficient means of improving mental health more generally. Furthermore, seeking to enhance career guidance and support services would be a pragmatic and ethically acceptable approach given that business faculty members are generally not clinically trained. An example of such a dual-purpose career planning technique is the Disney strategy that seeks to develop specific cognitive competencies based on how Walt Disney realised his dreams (Dilts 1995). The Disney strategy is reported as being a useful career guidance approach that has not only helped students foster a clearer future vision but also foster positive emotions, contributing to better mental health (Kotera 2018; Kotera and Sheffield 2017). This type of practical career exercise could be embedded in the business education curriculum without excessive training or logistical demands on education providers. Furthermore, such an eclectic psychological approach to improving resilience and general levels of well-being (i.e. rather than using psychotherapy directly) may attract and engage business students more fruitfully, as this group of students typically report high levels of shame towards mental health problems (Kotera et al. 2018a).

Consistent with findings from previous studies (e.g. DeMarie and Aloise-Young 2003), the observed high levels of extrinsic motivation amongst business students were not unexpected given that a key focus of the business world is income generation. Although there are reports of a shift amongst business students towards more intrinsic forms of motivation (FTI Consulting 2015; Hurst et al. 2016), business remains an extrinsically driven subject (Kotera et al. 2018a). Indeed, as van Luttervelt suggested (2006), business education programmes may be subject to a form of self-selection bias due to appealing to students that are already highly extrinsically motivated. In the current study, this extrinsic motivation was positively associated with beliefs concerning others' unethical behaviours, implying that business students who are extrinsically motivated tend to apply ethical judgements more to others' behaviour rather than their own. More specifically, whilst the present sample of business students found the unethical behaviour in the vignettes presented to be largely unacceptable and indicated they would not demonstrate such behaviour themselves, they believed that others would. In addition to the aforementioned narcissistic tendencies of some business professionals (Sautter et al. 2008), an explanation for this may relate to the competitive nature of business that necessitates evaluating a competitor's position and affirming one's own perceived strengths (Kotera et al. 2018a).

In terms of the implications of this study, attempts have been made to enhance business students' levels of intrinsic motivation by incorporating (for example) Bain's best teaching practices (2004), cognitive evaluation theory (CET; Deci et al. 1999), hands-on activities (Bergin 1999) and the "4Cs" of intrinsic motivation (control, challenge, curiosity and contextualisation; Lepper 1988) (McEvoy 2011). Although the effects of such interventions were shown to be inconsistent amongst different groups of postgraduate business students (i.e. business 
administration and human resources students), both quantitative and qualitative data indicate that CET was of the greatest benefit in terms of augmenting students' levels of intrinsic motivation. According to CET, students' intrinsic motivation (i.e. genuine interest in the subject) would be undermined if they are presented with an extrinsic reward (e.g. grade) (Kotera et al. 2018c). Consequently, CET-based efforts to enhance intrinsic motivation have focussed on introducing engaging learning-oriented activities such as reading "fun" materials and self-awareness diaries (i.e. with the aim of shifting students' focus from their grade to their learning; McEvoy 2011). Thus, whilst business educators should implement a balanced approach such that business students do not devalue the importance of their grade and other external indicators of success, introducing learning techniques that engage business students in the learning process could address the high rates and negative mental health consequences of extrinsic motivation (e.g. high levels of depression, stress and anxiety; Kotera et al. 2018b) amongst this student group.

Helping business students relate to and understand their ikigai (“生き甲斐”, a Japanese word roughly translated as having a reason to live; Yamamoto-Mitani and Wallhagen 2002) may also be a useful means of augmenting intrinsic motivation. In recent years, the concept of ikigai has grown in significance within the fields of both positive psychology and career guidance, with outcomes of psychological well-being being reported (Buettner 2017; García and Miralles 2017). Indeed, a strong sense of ikigai is related to a high quality of life as well as good mental health (Ishida 2012). A consultation with 15 managers and HR employees in Japan noted that ikigai encompasses many of the characteristics of intrinsic motivation (Author 1, personal communication, April 19, 2018). Business students could be led to "find their ikigai" using a framework considering not only their potential future income and career trajectory but also their inherent passion and skills as well as the wider needs of society (García and Miralles 2017). Such an approach may help to prevent business students from becoming "strategic learners" who are extrinsically motivated to earn a degree, but not intrinsically motivated to learn the subject (Bain 2004; Kotera et al. 2018b).

Whilst comparing and judging others' behaviours (i.e. as a form of self-validation) can cause negative psychological effects such as envy and depression (Johnson and Knobloch-Westerwick 2014; Pera 2018), these can be mitigated via the cultivation of self-compassion that serves as a protective factor for psychopathology (Neff 2003b). This is in line with findings from the present study demonstrating that self-compassion was a significant explanatory variable for all of the mental health symptoms. It is also in line with previous research into the health concomitants of self-compassion (e.g. Neff 2003a, b), as well as research into compassion-infused meditation interventions that have demonstrated a range of salutary mental health outcomes, including in business professionals (Shonin and Van Gordon 2015; Shonin et al. 2014a, b).

By introducing aspects of these interventions into business education curricula, not only can students and business workers improve their overall levels of well-being, but as demonstrated by a randomised controlled trial of middle-managers, they can also improve overall levels of job performance and job satisfaction (Shonin et al. 2014a). This has wider implications for the design of organisational-level interventions that will always be more palatable where they can demonstrate either monetary or performance gains. Furthermore, compassion-infused approaches may be a skilful means of improving ethical judgement because (i) as demonstrated by this study's findings, self-compassion was a significant explanatory variable for ethical judgement and (ii) business lecturers in general do not believe that teaching ethics improves students' ethical judgement (Lund Dean and Mullins Beggs 2006).

Although this study offers unique insights into the factors that influence ethical judgement in UK business students, there are several limitations to consider. Firstly, participants were recruited 
from one academic institution; hence, factors unique to the university (e.g. student recruitment profiles, learning and assessment styles, teaching quality, student support) may have influenced the findings (Kotera et al. 2018a). Secondly, using self-report measures for mental health issues may have limited the accuracy of the participant responses because of social desirability bias (Latkin et al. 2017). Lastly, as with all cross-sectional studies, the study was limited by the fact that it is not possible to ascertain the causal direction of the relationships identified.

Business ethics have come under increasing scrutiny over the past few years due to various corporate scandals. This has prompted a need for further research into the characteristics of people who are drawn to the business world as a career as well as the education they receive. Whilst many business schools have focused on the ethics element of business education (Litzky and MacLean 2011), such training approaches have not been particularly effective in improving ethical judgement (Jewe 2008; Lampe and Engleman-Lampe 2012; Mullins Beggs and Lund Dean 2007). Findings from the present study indicate that in conjunction with building a stronger awareness of business ethics, business ethics education programmes may be more effective if they provide business students with the resources to regulate and maintain their mental health. More specifically, outcomes from this study indicate that by augmenting intrinsic motivation and selfcompassion, business students may experience reduced mental health problems and demonstrate more ethical behaviour (Jordan and Monin 2008). Future, more longitudinal research involving university business is thus warranted to replicate the findings of this study's students as well as evaluate the effectiveness of interventions that implement the aforementioned recommendations.

\section{Compliance with Ethical Standards}

Conflict of Interest The authors declare that they have no conflict of interest.

Ethical Approval All procedures followed were in accordance with the ethical standards of the responsible committee on human experimentation (University of Derby, UK) and with the Helsinki Declaration of 1975, as revised in 2000 (5).

Informed Consent Informed consent was obtained from all patients prior to being included in the study.

Open Access This article is distributed under the terms of the Creative Commons Attribution 4.0 International License (http://creativecommons.org/licenses/by/4.0/), which permits unrestricted use, distribution, and reproduction in any medium, provided you give appropriate credit to the original author(s) and the source, provide a link to the Creative Commons license, and indicate if changes were made.

Publisher's Note Springer Nature remains neutral with regard to jurisdictional claims in published maps and institutional affiliations.

\section{References}

Agle, B. R., Hart, D. W., Thompson, J. A., \& Hendricks, H. M. (Eds.). (2014). Research companion to ethical behavior in organizations: constructs and measures. Northampton: Edward Elgar.

Ahmed, M. M., Chung, K. Y., \& Eichenseher, J. W. (2003). Business students' perception of ethics and moral judgment: a cross-cultural study. Journal of Business Ethics, 43(1-2), 89-102. https://doi.org/10.1023 /A:1022915316112. 
Bain, K. (2004). What the best college teachers do. Cambridge: Harvard University Press.

Bergin, D. A. (1999). Influences on classroom interest. Educational Psychologist, 34, 87-98.

Breines, J. G., \& Chen, S. (2012). Self-compassion increases self-improvement motivation. Personality and Social Psychology Bulletin, 38(9), 1133-1143. https://doi.org/10.1177/0146167212445599.

Brown, K. W., \& Ryan, R. M. (2003). The benefits of being present: mindfulness and its role in psychological well-being. Journal of Personality and Social Psychology, 84(4), 822-848. https://doi.org/10.1037/0022-3514.84.4.822.

Brown, G. S., \& Strange, C. (1981). The relationship of academic major and career choice status to anxiety among college freshmen. Journal of Vocational Behavior, 19, 328-334.

Brown, T. A., Sautter, J. A., Littvay, L., Sautter, A. C., \& Bearnes, B. (2010). Ethics and personality: empathy and narcissism as moderators of ethical decision making in business students. Journal of Education for Business, 85(4), 203-208.

Buettner, D. (2017). The blue zones of happiness: a blueprint for a happier life. Washington, D.C.: National Geographic.

Cialdini, R. B., Petrova, P. K., \& Goldstein, N. J. (2004). The hidden costs of organizational dishonesty. MIT Sloan Management Review Retrieved from https://sloanreview.mit.edu/article/the-hidden-costs-oforganizational-dishonesty/. Accessed 15 May 2018

Cole, B.C., \& Smith, D.L. (1996). Perceptions of business ethics: Students vs. business people. Journal of Business Ethics, 15(8), 889-896. https://doi.org/10.1007/BF00381856.

Comegys, C., Vaisanen, J., Lupton, R. A., \& Rawlinson, D. R. (2013). Attitudes towards business ethics and degree of opinion leadership of future managers in the United States, Finland, and China. Journal of International Education Research, 9(1), 7-20. https://doi.org/10.19030/jier.v9i1.7495.

Dahlin, M., Nilsson, C., Stotzer, E., \& Runeson, B. (2011). Mental distress, alcohol use and help-seeking among medical and business students: a cross-sectional comparative study. BMC Medical Education, 11(92). https://doi.org/10.1186/1472-6920-11-92.

Deci, E. L., Koestner, R., \& Ryan, R. M. (1999). A meta-analytic review of experiments examining the effects of extrinsic rewards on intrinsic motivation. Psychological Bulletin, 126, 627-668.

DeMarie, D., \& Aloise-Young, P. A. (2003). College students' interest in their major. College Student Journal, $37,462-469$.

Dilts, R. (1995). Strategies of genius: volume one. Cupertino: Meta.

Ethics Resource Center. (2014). National business ethics survey of the U.S. workforce. Arlington: Author.

FTI Consulting. (2015). Allstate/national journal heartland monitor xxii key findings. Baltimore: Author.

García, H., \& Miralles, F. (2017). Ikigai: the Japanese secret to a long and happy life. London: Hutchinson.

Germeijs, V., Verschueren, K., \& Soenens, B. (2006). Indecisiveness and high school students' career decisionmaking process: longitudinal associations and the mediational role of anxiety. Journal of Counseling Psychology, 53(4), 397-410.

Ghoshal, S. (2005). Bad management theories are destroying good management practice. Academy of Management Learning \& Education, 4(1), 75-91. https://doi.org/10.5465/AMLE.2005.16132558.

Groberman, A. (2017). Difference between stress and anxiety. Retrieved from http://www.psyweb. com/articles/anxiety/difference-between-stress-and-anxiety. Accessed 30 May 2018

Haski-Leventhal, D., \& Concato, J. (2016). The state of CSR and RME in business schools and the attitudes of their students. North Ryde: Macquarie Graduate School of Management.

Higher Education Statistics Agency. (2018). Higher education student data. London: Author.

Hindmarch, T., Hotopf, M., \& Owen, G. (2013). Depression and decision-making capacity for treatment or research: a systematic review. BMC Medical Ethics, 14, 54. https://doi.org/10.1186/1472-6939-14-54.

Hoaglin, D. C., \& Iglewicz, B. (1987). Fine-tuning some resistant rules for outlier labeling. Journal of the American Statistical Association, 82(400), 1147-1149. https://doi.org/10.1080/01621459.1987.10478551.

Hurst, A., Pearce, A., Parish, S., Erickson, C., Schnidman, A., Vesty, L., Garlinghouse, M., \& Pavela, A. (2016). Purpose at work: the largest global study on the role of purpose in the workforce, Retrieved from https://business.linkedin. com/content/dam/me/business/en-us/talent-solutions/resources/pdfs/Global-Report-on-Purpose-at-Work.pdf.

Ishida, R. (2012). Purpose in life (ikigai), a frontal lobe function, is a natural and mentally healthy way to cope with stress. Psychology, 3(3), 272-276. https://doi.org/10.4236/psych.2012.33038.

Jewe, R. D. (2008). Do business ethics courses work? The effectiveness of business ethics education: an empirical study. The Journal of Global Business Issues, 2(1), 1-6.

Johnson, B. K., \& Knobloch-Westerwick, S. (2014). Glancing up or down: mood management and selective social comparisons on social networking sites. Computers in Human Behavior, 41(0), 33-39. https://doi. org/10.1016/j.chb.2014.09.009.

Jordan, A., \& Monin, B. (2008). From sucker to saint: moralization in response to self-threat. Psychological Science, 19(8), 809-815. https://doi.org/10.1111/j.1467-9280.2008.02161.x.

Kasser, T., \& Ryan, R. M. (2001). Be careful what you wish for: Optimal functioning and the relative attainment of intrinsic and extrinsic goals. In P. Schmuck \& K. M. Sheldon (Eds.), Life goals and well-being: Towards a positive psychology of human striving (pp. 116-131). Goettingen: Hogrefe \& Huber. 
Kimes, H. G., \& Troth, W. A. (1974). Relationship of trait anxiety to career decisiveness. Journal of Counseling Psychology, 21(4), 277-280.

Kotera, Y. (2018). A qualitative investigation into the experience of neuro-linguistic programming certification training among Japanese career consultants. British Journal of Guidance and Counselling, 46(1), 39-50. https://doi.org/10.1080/03069885.2017.1320781.

Kotera, Y., \& Sheffield, D. (2017). Disney strategy for Japanese university students' career guidance: a mixed methods pilot study. Journal of the National Institute for Career Education and Counselling, 38, 52-61. https://doi.org/10.20856/jnicec.3808.

Kotera, Y., Conway, E., \& Van Gordon, W. (2018a). Mental health of UK university business students: relationship with shame, motivation and self-compassion. The Journal of Education for Business, 1-10. https://doi.org/10.1080/08832323.2018.1496898.

Kotera, Y., Adhikari, P., \& Van Gordon, W. (2018b). Motivation types and mental health of UK hospitality workers. International Journal of Mental Health and Addiction, 16, 751-763. https://doi.org/10.1007 /s11469-018-9874-z.

Kotera, Y., Adhikari, P., \& Van Gordon, W. (2018c). The relationship between work motivation and worker profile in UK hospitality workers. International Journal of Education, Psychology and Counseling, 2(6), 231-243.

Lampe, M., \& Engleman-Lampe, C. (2012). Mindfulness-based business ethics education. Academy of Educational Leadership Journal, 16(3), 99-111.

Langer, E. J. (1989). Mindfulness. Reading: Addison Wesley.

Langer, E. J. (2005). Well-being: Mindfulness versus positive evaluation. In C. R. Snyder \& S. J. Lopez (Eds.), Handbook of positive psychology (pp. 214-230). New York: Oxford University Press.

Latkin, C. A., Edwards, C., Davey-Rothwell, M. A., \& Tobin, K. E. (2017). The relationship between social desirability bias and self-reports of health, substance use, and social network factors among urban substance users in Baltimore, Maryland. Addictive Behaviors, 73, 133-136. https://doi.org/10.1016/j. addbeh.2017.05.005.

Leary, M. R., Tate, E. B., Adams, C. E., Allen, A. B., \& Hancock, J. (2007). Self-compassion and reactions to unpleasant self-relevant events: the implications of treating oneself kindly. Journal of Personality and Social Psychology, 92(8), 887-904. https://doi.org/10.1037/0022-3514.92.5.887.

Lepper, M. R. (1988). Motivational considerations in the study of instruction. Cognition and Instruction, 5, $289-309$.

Litzky, B. E., \& MacLean, T. L. (2011). Assessing business ethics coverage at top U.S. business schools. In D. L. Swanson \& D. G. Fisher (Eds.), Toward assessing business ethics education (pp. 133-142). Charlotte: Information Age Publishing.

Long, M., \& Rao, S. (1995). The wealth effects of unethical business behavior. Journal of Economics and Finance, 19(2), 65-73. https://doi.org/10.1007/BF02920510.

Lovibond, S. H., \& Lovibond, P. F. (1995). Manual for the depression anxiety stress scales (2nd ed.). Sydney: Psychology Foundation.

Lund Dean, K., \& Mullins Beggs, J. (2006). University professors and teaching ethics: conceptualizations and expectations. Journal of Management Education, 30(1), 15-44. https://doi.org/10.1177/1052562905280839.

Lund Dean, K., Mullins Beggs, J., \& Keane, T. (2010). Mid-level managers, organizational context, and (un)ethical encounters. Journal of Business Ethics, 97(1), 51-69. https://doi.org/10.1007/s10551-0100495-0.

Matthews, V. (2017). Mental health at business school: 'the anxiety was overwhelming'. Financial Times. Retrieved from https://www.ft.com/content/e3824c38-81c3-11e7-94e2-c5b903247afd. Accessed 15 May 2018

Matthews, C., \& Gandel, S. (2015). The 5 biggest corporate scandals of 2015. Fortune. Retrieved from http://fortune.com/2015/12/27/biggest-corporate-scandals-2015/. Accessed 15 May 2018

Matthews, C., \& Heimer, M. (2016). The 5 biggest corporate scandals of 2016. Fortune. Retrieved from http://fortune.com/2016/12/28/biggest-corporate-scandals-2016/. Accessed 15 May 2018

Mccabe, D., Butterfield, K., \& Trevino, L. K. (2006). Academic dishonesty in graduate business programs: prevalence, causes, and proposed action. Academy of Management Learning \& Education, 5(3), 294-305.

McEvoy, G. M. (2011). Increasing intrinsic motivation to learn in organizational behavior classes. Journal of Management Education, 35(4), 468-503. https://doi.org/10.1177/1052562911408098.

Mullins Beggs, J., \& Lund Dean, K. (2007). Legislated ethics or ethics education? Faculty views in the postEnron era. Journal of Business Ethics, 71, 15-37. https://doi.org/10.1007/s10551-006-9123-4.

Neely, M. E., Schallert, D. L., Mohammed, S. S., Roberts, R. M., \& Chen, Y.-J. (2009). Self-kindness when facing stress: the role of self-compassion, goal regulation, and support in college students' well-being. Motivation and Emotion, 33, 88-97. https://oi.org/10.1007/s11031-008-9119-8.

Neff, K. (2003a). Self-compassion: an alternative conceptualization of a healthy attitude toward oneself. Self and Identity, 2(2), 85-101. https://doi.org/10.1080/15298860309032. 
Neff, K. (2003b). The development and validation of a scale to measure self-compassion. Self and Identity, 2(3), 223-250. https://doi.org/10.1080/15298860309027.

Neff, K., \& Vonk, R. (2009). Self-compassion versus global self-esteem: two different ways of relating to oneself. Journal of Personality, 77(1), 23-50. https://doi.org/10.1111/j.1467-6494.2008.00537.x.

Odonkor, A. (2017). The costs and benefits of ethics in business. LinkedIn. Retrieved from https://www.linkedin. com/pulse/costs-benefits-ethics-business-alexander-ayertey-odonkor-msc-bsc/. Accessed 15 May 2018

Pera, A. (2018). Psychopathological processes involved in social comparison, depression, and envy on Facebook. Frontiers in Psychology, 9. https://doi.org/10.3389/fpsyg.2018.00022.

Reidenbach, R. E., \& Robin, D. P. (1990). Toward the development of a multidimensional scale for improving evaluations of business ethics. Journal of Business Ethics, 9(8), 639-653.

Sautter, J., Brown, T., Littvay, L., Sautter, A., \& Bearnes, B. (2008). Attitude and divergence in business students: an examination of personality differences in business and non-business students. Electronic Journal of Business Ethics and Organization Studies, 13(2), 70-78.

Sheldon, K. M., \& Kasser, T. (1995). Coherence and congruence: two aspects of personality integration. Journal of Personality and Social Psychology, 68(3), 531-543. https://doi.org/10.1037/0022-3514.68.3.531.

Sheldon, K. M., \& Kasser, T. (1998). Pursuing personal goals: skills enable progress, but not all progress is beneficial. Personality and Social Psychology Bulletin, 24(12), 1319-1331. https://doi.org/10.1177 /01461672982412006.

Shields, R., Comegys, C., Lupton, R., \& Takei, H. (2013). Undergraduate attitudes toward business ethics: a cross-cultural comparison. Journal of Studies in Education, 3(4), 72-80. https://doi.org/10.5296/jse.v3 i4.4179.

Shonin, E., \& Van Gordon, W. (2015). Managers' experiences of meditation awareness training. Mindfulness, 4, 899-909.

Shonin, E., Van Gordon, W., Dunn, T., Singh, N., \& Griffiths, M. D. (2014a). Meditation awareness training for work-related wellbeing and job performance: a randomized controlled trial. International Journal of Mental Health and Addiction, 12, 806-823.

Shonin, E., Van Gordon, W., \& Griffiths, M. D. (2014b). The treatment of workaholism with meditation awareness training: a case study. Explore: The Journal of Science and Healing, 10, 193-195.

Shonin, E., Van Gordon, W., Garcia-Campayo, J., \& Griffiths, M. D. (2017). Can compassion help cure healthrelated disorders? British Journal of General Practice, 67(657), 177-178. https://doi.org/10.3399/bjgp17 X690341.

Tukey, J. W. (1962). The future of data analysis. Annals of Mathematical Statistics, 33(1), 1-67.

Van Gordon, W., Shonin, E., Zangeneh, M., \& Griffiths, M. D. (2014). Work-related mental health and job performance: can mindfulness help? International Journal of Mental Health and Addiction, 12, 129-137.

Van Gordon, W., Shonin, E., \& Griffiths, M.D. (2016). Are contemporary mindfulness-based interventions unethical? British Journal of General Practice, 66(643), 94. https://doi.org/10.3399/bjgp16X683677.

van Luttervelt, L. (2006). Business education and corporate misbehavior (Master thesis). Maastricht University, Maastricht.

Varca, P. E., \& James-Valutis, M. (1993). The relationship of ability and satisfaction to job performance. Applied Psychology, 42(3), 265-275. https://doi.org/10.1111/j.1464-0597.1993.tb00742.x.

Wallace, A. B., \& Shapiro, S. L. (2006). Mental balance and wellbeing: building bridges between Buddhism and Western psychology. American Psychologist, 61, 690-701. https://doi.org/10.1037/0003-066X.61.7.690.

Wang, X., Chen, Z., Poon, K.-T., Teng, F., \& Jin, S. (2017). Self-compassion decreases acceptance of own immoral behaviors. Personality and Individual Differences, 106, 329-333. https://doi.org/10.1016/j. paid.2016.10.030.

Waples, E., Antes, A., Murphy, S., Connelly, S., \& Mumford, M. (2009). A meta-analytic investigation of business ethics instruction. Journal of Business Ethics, 87(1), 133-151. https://doi.org/10.1007/s10551-0089875-0.

Webley, S., \& More, E. (2003). Does business ethics pay?: ethics and financial performance. London: Institute of Business Ethics.

Williams, G. C., Cox, E. M., Hedberg, V. A., \& Deci, E. L. (2000). Extrinsic life goals and health risk behaviors in adolescents. Journal of Applied Social Psychology, 30(8), 1756-1771. https://doi.org/10.1111/j.15591816.2000.tb02466.x.

Yamamoto-Mitani, N., \& Wallhagen, M. (2002). Pursuit of psychological well-being (ikigai) and the evolution of self-understanding in the context of caregiving in Japan. Culture, Medicine and Psychiatry, 26(4), 399-417. https://doi.org/10.1023/A:1021747419204.

Ying, Y.-W. (2009). Contribution of self-compassion to competence and mental health in social work students. Journal of Social Work Education, 45(2), 309-323. https://doi.org/10.5175/JSWE.2009.200700072. 